\title{
Training Faculty for Ethics Across the Curriculum
}

\author{
Marilyn A. Dyrud \\ Oregon Institute of Technology
}

\section{Introduction}

Ethics has been an important topic for a number of years in many disciplines. With blatantly unethical and highly publicized situations occurring in major companies, it behooves us more than ever, as instructors, to make a conscious effort to integrate ethics into all of our courses, regardless of academic area or students' level of achievement. Some instructors, however, may feel that they are not knowledgeable enough in the field of ethics to broach the subject in class, let alone deal with complex cases.

In 1996, Oregon Institute of Technology made its first formal foray into ethics across the curriculum, via a series of faculty seminars. I served as facilitator because I had undertaken special training in that area, specifically the NSF-funded "Ethics Across the Curriculum" workshop at the Center for the Study of Ethics in the Professions (CSEP) at Illinois Institute of Technology and three week-long summer seminars at the University of Montana, offered by the Association for Practical and Professional Ethics.

A cross-curricular approach seemed natural for a small school such as OIT. Only one standalone professional ethics course is available for students, and only the Civil Engineering Department requires it. Even though the course regularly fills, our students have little room in their crowded technical curricula for free electives, and so an across-the-curriculum approach would, we thought, appeal to expressed faculty desires to address ethics education.

Faculty training for ethics across the curriculum is not mandatory, since most do not teach ethics per se and primarily want to increase student awareness of thorny issues and situations they may encounter on the job. However, after my CSEP experience, I was convinced that training is desirable and definitely helpful for faculty who are interested in integrating ethics but have no formal education in the field.

The goal of OIT's seminars was to equip faculty with enough information, resource materials, and skills to effectively integrate ethics education into technical classes, without sacrificing technical content. To date, more than 40 faculty, about one-third of OIT's instructors, have participated, with a final series planned for 2000. This paper explains our efforts, focusing on the nuts and bolts of seminar development and implementation: securing funding, dealing with logistics, choosing faculty, conducting the series, and evaluating results.

\section{Securing Funding}

Administrative support, both financial and psychological, is essential for the success of this type 
of project. While on the surface, minimal funding is necessary, there are some hidden costs, such as released time for the facilitator to prepare materials. Faculty interested in starting a similar training program on their own campuses should speak frequently with administration and provide a list of budgetary needs including materials, xeroxing, refreshments (to stoke late afternoon creative fires), and adjunct course coverage. The latter will depend on the method of implementation, but for the first two years, I received .25 released time for two quarters (one to prepare materials and the other to teach the seminars), and for the past two years, I have received .25 for one quarter, since I have now collected all necessary materials. Overall, cost is low and the benefits of faculty training certainly outweigh financial considerations.

\section{Dealing with Logistics}

Where to hold the seminars is an important consideration. Since one goal is to encourage energetic and fruitful discussion, a regular classroom with rows of desks is not attractive. Movable furniture and tables are much more conducive to small group activities, one of the methodologies useful for discussing topics such as ethics.

Finding a meeting time for busy faculty also proves challenging. Technical faculty, in particular, have high student contact hours because of labs, which are scheduled from early morning to late evening on our campus. A mid-week, late afternoon slot was the most appropriate time.

\section{Choosing Faculty}

I have had the luxury of hand-choosing faculty participants. Selection criteria include an expressed interest in ethics, a willingness to participate, and openness about sharing materials with departmental peers. During the first year, participants hailed from our School of Engineering and Industrial and Technologies (engineering, engineering technology, and business). The second year drew from the School of Health and the Arts and Sciences (communications, social sciences, mathematics, physics, natural sciences, dental hygiene, and medical imaging). And for the past two years, faculty were invited from all of these fields. In addition, administrators have attended, including the deans from both schools as well as the provost. Conspicuous administrative involvement has lent support to the whole venture and given a tacit seal of approval.

I have also encouraged new faculty to participate, as this offers them a chance to develop relationships with faculty outside of their home departments. For all four years, groups have bonded well, thus enhancing the overall value of the seminar and encouraging cross-curricular activities that extend beyond the seminar meetings.

\section{Conducting the Seminars}

While the materials and information from the CSEP workshop provided a basic blueprint, our faculty needed some real "hands-on" materials to work with, as well as a discussion format that allowed them to voice their opinions and concerns. 


\section{Materials Development}

To meet faculty need for practical and immediately usable materials, I spent my .25 released time for the terms prior to the first and second seminars creating resource notebooks for participants. The goal was to provide faculty with background information on applied ethics and appropriate ethical theories, cases suitable for 50-minute class periods, and actual course materials. The result was a 1/2" binder divided into several sections:

- Copies of professional codes of ethics

- Information on current issues in a variety of fields, types of ethical problems, and stages of moral development

- Course materials, including transparency masters as well as handouts for students

- A section listing ethics centers, ethics cases, videos, Internet sites, and OIT library resources, with an annotated bibliography of library holdings

- Selected readings for discussion ${ }^{1}$

Participants also cheerfully bring materials to share, such as articles, codes, classroom exercises, or recent ethical situations they have encountered.

\section{Seminar Meetings}

Faculty meet once a week for eight weeks during winter term, with each session lasting about 90 minutes. Time varies according to the intensity of discussions. A typical schedule looks like this:

\section{Week Topic}

$1 \quad$ Why are we here and what are we doing?

2 Problem-solving activity

$3 \quad$ Issues

$4 \quad$ Integration methodology

$5 \quad$ Integration methodology

$6 \quad$ Participant reports

$7 \quad$ Participant reports

$8 \quad$ Wrap up and evaluation; graduation

Every year, after the second formal meeting, a curious thing happens: our meetings spontaneously grow, as faculty congregate in offices and hallways for pre- and post-meeting discussions, a sure sign of intellectual involvement with the topic.

Meetings include a variety of pedagogical techniques, which mirror those used in a student classroom and which appeal to various learning styles: large group discussions, small group activities, writing, informal presentations. 
"Hands-on," experiential exercises work extremely well; for example, we have played LockheedMartin's Ethics Challenge Game, and while some were bothered by the corporate nature of "right" answers, the game is a valuable tool for allowing participants to explore their own values in relation to the game's scenarios and to help them understand that knowledge of their personal stage of ethical development will impact their teaching. A follow-up exercise, based on Kohlberg's stages of cognitive development, also helps faculty sort out where they personally rate in terms of their own ethical development.

Using a narrative approach is also successful: encouraging participants to share their own experiences promotes bonding in the group and also allows others to chime in, offering similar experiences. For example, as the first small group activity, I use a short case that actually happened to me (Figure 1).

\section{A Teaching Scenario}

Sam, a C student, is taking one of your classes and is scheduled to give a presentation on Tuesday. You walk into class, and Sam is not there.

When you return to your office after the two-hour class, your phone message light is blinking. The message is from Sam, logged in by Audix [the campus voice mail service] at five minutes after the start of class and from a campus extension. Sam says he is stuck in small town north of the city, with car troubles.

You run into Sam the next day and ask him about his car, then note that his call was from a campus extension. He insists he was stuck with his car and wants to make up his presentation.

What do you do?

Figure 1. Sample small group activity

Faculty split into small groups to discuss the scenario and formulate an answer. Their responses are typically overwhelmingly negative; most faculty recommend failing the student for that assignment and taking him to task for lying. However, I took a different tack: this is a course in public speaking, and this very taciturn student hates speaking in front of groups; it is torture for him. So I allowed him to give his presentation, knowing that this solution was appropriate (and, in a sense, a "punishment" in itself) and that the student could not later accuse me of being unfair and inflexible.

\section{Faculty Projects}

Seminar participants have developed an impressive list of techniques for integrating ethics into their courses. These are the results of projects, based on the CSEP model: faculty choose a day in one of their classes, "do" something with ethics, and report back to the larger group during weeks 6 and 7. Below is a partial list of techniques: 
- Use cases and videos

- Develop short "pithy" scenarios related to issues in the field

- Distribute and discuss professional codes

- Have students read professional literature in the field and report back to class (a group activity)

- Ask students to interview working professionals for their thoughts on ethics; report back to class or write a short memo

- Adapt some of the exercises from Classroom Assessment Techniques (Angelo and Cross, 1993) to focus on ethics

- Take a "regular" problem and add an ethical dimension

- Take advantage of "serendipitous" occasions: newspaper articles, cases of plagiarism, etc.

Projects that faculty have developed for their classes have been surprisingly varied and creative:

- Number-crunch Ford Pinto gas tank redesign statistics (accounting)

- Examine the Hyatt Regency walkways collapse (civil engineering)

- Explore why a corporation persistently includes a deceased employee's resume in grant applications (technical writing)

- View Stalking the Wily Hacker and discuss issues of database privacy (computer software)

- Discuss data distortion (statistical methods)

- Discuss the technician's role in maintaining confidentiality in relation to death and dying issues (medical imaging)

- Discuss fictional characters' ethical stances (literature)

- Discuss data manipulation (environmental sciences)

- Discuss Nazi technical memoranda (technical writing)

- Discuss whistleblowing (mechanical engineering technology)

- Write a personal mission statement based on Covey's The 7 Habits of Highly Effective People (technical communication)

- Assess the environmental impact of a proposed ski resort on water quality and wildlife (applied environmental sciences)

Seminar participants report that students willingly engage in these projects, regardless of class size, and that even in the quietest of classes, discussion is energetic. When I ask them if they will include ethics in future classes, the answer is a resounding "Yes!"

\section{Evaluating Results}

After the final meeting, participants complete an informal written evaluation of the series, answering questions regarding the resource notebook; number, length, and quality of meetings; seminar leader; seminar value, both personal and pedagogical; and recommendations for improvement. Feedback has been excellent: all have been very satisfied with the experience and are eager to include ethics in their courses.

One participant spoke of the weekly meeting as "an oasis," removed from daily pedantic concerns. Others expressed a mild postpartum: "I really enjoyed all of the meetings and hated to see them end. I think a few more would have been beneficial." And yet another indicated 
that the seminars gave her a foundation for approaching the general field of ethics in technology courses: "I appreciated the suggestions regarding differentiating professional ethics from personal morality issues, as students tend to get 'hung up' on the familiar and be less aware of the concept of "professional' ethics."

Faculty also appreciated the resources notebook--"Very helpful, well laid out. Good materials I can go back to and use in the future"--as well as the informal atmosphere of the meetings and the facilitator's style: "You did an excellent job leading with an invisible hand. You introduced cases and ethical subjects and allowed us to explore these topics in depth. On several issues, I imagine you may not have agreed with our analysis. However, you allowed us to learn and explore without telling us the 'answer.' I appreciate this. You were an effective leader."

In four years, only two faculty have offered a recommendation for improvement: to distribute the class project earlier, perhaps as early as the second meeting. These faculty teach very contentdense classes and had trouble popping in an extra topic without substantial prior notice. This is a good suggestion, and I will implement it next term.

\section{Conclusions}

Judging from evaluations, OIT's ethics seminars are successful and achieve their stated goals: to acquaint faculty with the field of applied ethics, provide relevant background, and arm them with skills and techniques to integrate ethics into their classes without sacrificing technical content. Professionally, the meetings remind faculty of their codes of conduct; pedagogically, faculty learn "hands-on" techniques for teaching ethics; and personally, many faculty have commented on the value of the discussions; for example, an engineering instructor noted, "It's always good to examine my own ethical sense and face my shortcomings (even if I only admit them to myself)."

Our work with ethics will not end with this year's seminars. We have collected a number of academic scenarios, based on actual teaching situations, that we hope to bind into a booklet and distribute to faculty. In addition, in winter term our Ethics Committee, composed of faculty who have been participants in the seminars, will begin meeting to write a code of ethics for the institution. And in spring, we plan a gala "reunion" for all previous seminar attendants, to trade stories and techniques. We will also have them complete a survey to determine if, and to what extent, our EAC seminars have impacted teaching and student awareness.

Has the ethics across the curriculum series been good for OIT? Absolutely: it has brought us closer together as a faculty and has generated true excitement on campus about the field of ethics. And, of course, it has allowed us to share vital information with our students, which they would not otherwise know. As Stephen H. Unger explains in Controlling Technology: Ethics and the Responsible Engineer, "Those who are developing and applying technology must take responsibility for the consequences of their work and play an active role in directing it toward humane ends." 


\section{References}

1. Portions of this article have been previously published by Illinois Institute of Technology. See Marilyn A. Dyrud, "Life After the Ethics Seminar," Perspectives on the Professions 17, no. 2 (Spring 1998): 7-9. Available from Center for the Study of Ethics in the Professions, Illinois Institute of Technology, Chicago, IL 60616-3793 (contact the editor, Michael Davis).

2. Unger, Stephen H. Controlling Technology: Ethics and the Responsible Engineer. 2nd ed. New York: John Wiley and Sons, 1994.

\section{MARILYN A. DYRUD}

Marilyn Dyrud is a full professor in the Communications Department at Oregon Institute of Technology. Her teaching includes courses in rhetoric, desktop publishing, editing, technical/business writing, public speaking, and professional ethics. She is active in ASEE as OIT's campus rep, ETD section rep, and a member of the ETC Publications Committee, for which she coordinates the annual engineering technology education bibliography. She is also active in the Association for Business Communication, the Association for Practical and Professional Ethics, and recently served as manuscript editor for the international anthology Stories from a Heated Earth: Our Geothermal Heritage, published by the International Geothermal Association/Geothermal Resources Council. 